\title{
Filling gaps in Aegean deep histories? Evaluating quartz concentrations from Koupharika-Krotiria on Kythera, Greece
}

Timothy E. Gregory ${ }^{1}$, P. Nick Kardulias ${ }^{2}$, Stavros A. Paspalas ${ }^{3}$, Konstantinos P. Trimmis ${ }^{4, *}$ \& Lita Tzortzopoulou-Gregory ${ }^{5}$

Recent archaeological survey on the Greek island of Kythera yielded prehistoric quartz that offers new information on the island's role in early Aegean occupation.

Keywords: Greece, Kythera, Aegean, prehistory, lithics

\section{Introduction}

The notion of deep history attempts to create "a seamless narrative that acknowledges the full chronology of the human past" through an interdisciplinary approach (Smail 2008: 3). Questions about Aegean deep histories, such as colonisation of the islands during the Palaeolithic and seafaring in the Early Aegean, are difficult to answer due to the absence of archaeological evidence that would assist in determining the routes between the islands, the Anatolian coast and mainland Greece. The absence of early sites on 'bridge' islands such as Kasos, Karpathos, Kythera or Santorini, combined with evidence for early humans in Crete, Naxos, Mani, Zakynthos, Kephalonia, Lesvos and the Karaburun peninsula in Turkey, creates a lacunose picture, which is difficult to interpret (for an overview, see Figure 1; Lawler 2018). The location of the island of Kythera, off the southern coast of the Peloponnese, suggests that it may have been important in early prehistory (see Gregory \& Tzortzopoulou-Gregory 2015).

The Australian Paliochora-Kythera Archaeological Survey (APKAS) is a joint project operating under the aegis of the Australian Archaeological Institute at Athens with significant input from The Ohio State University. Its initial field seasons (1999-2003) aimed to investigate the broad question of the relationship between Kythera's medieval fortified centres and their hinterlands (Coroneos et al. 2002: 127). Today, the project has significantly expanded its research area, covering most of the northern part of the island while maintaining its originally conceived diachronic approach (Figure 2). In the summer of 2016, the APKAS

1 Department of History, The Ohio State University, Dulles Hall, Columbus, OH 43210, USA

2 Program in Archaeology, The College of Wooster, Kanke Hall, Wooster, OH 44691, USA

3 The Australian Archaeological Institute at Athens, Madsen Building (F09), The University of Sydney, Sydney 2006, Australia

4 Department of Anthropology and Archaeology, University of Bristol, 43 Woodland Road, Bristol BS8 1UU, UK

5 The Australian Archaeological Institute at Athens, Athens Office Zacharitsa 17, Koukaki, Athens 11741, Greece

* Author for correspondence (Email: kostas.trimmis@bristol.ac.uk)

(c) Antiquity Publications Ltd, 2019

ANTIQUITY 93 367, e3 (2019): 1-8

https://doi.org/10.15184/aqy.2019.5 
Timothy E. Gregory et al.

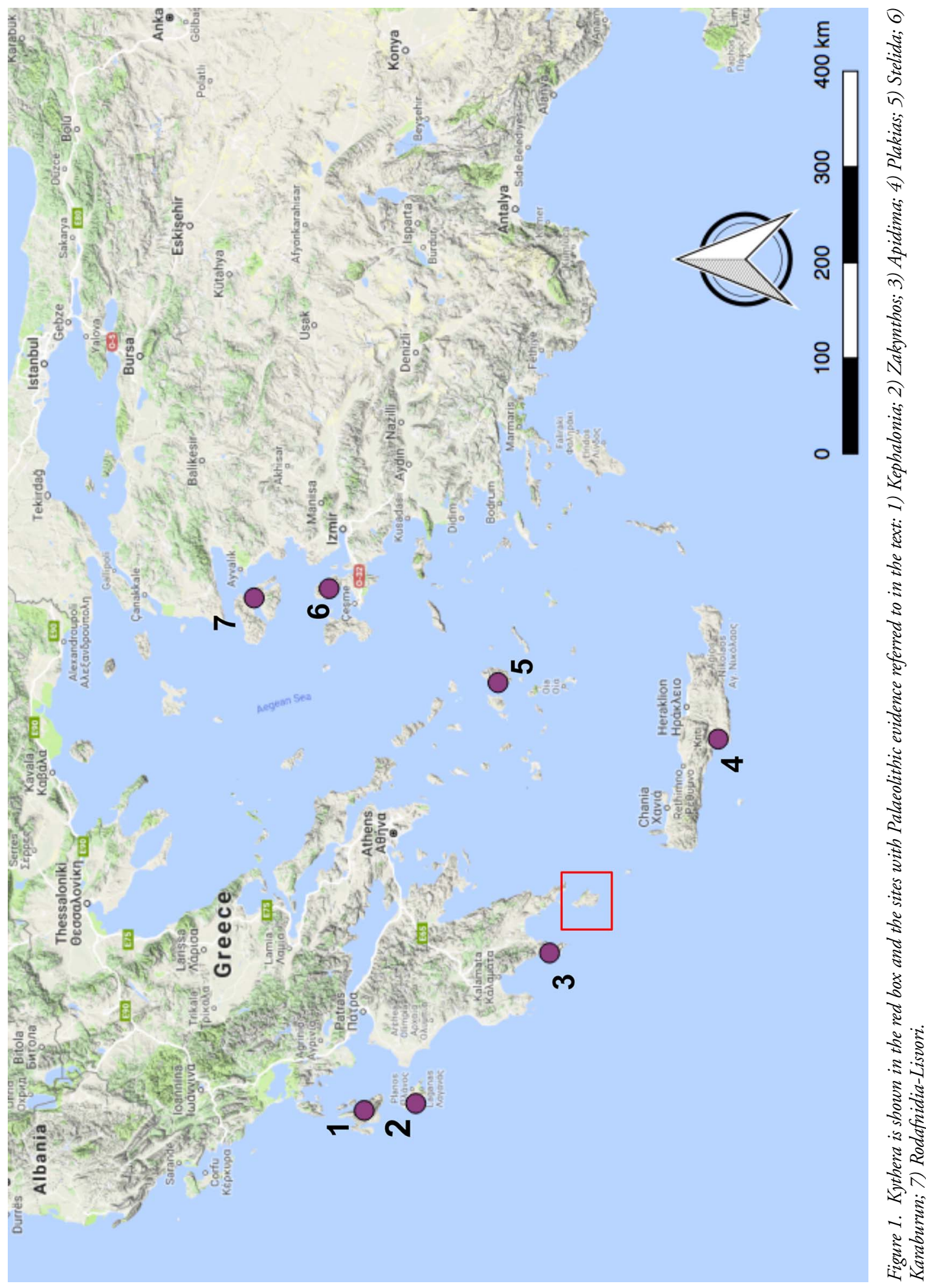

(C) Antiquity Publications Ltd, 2019 


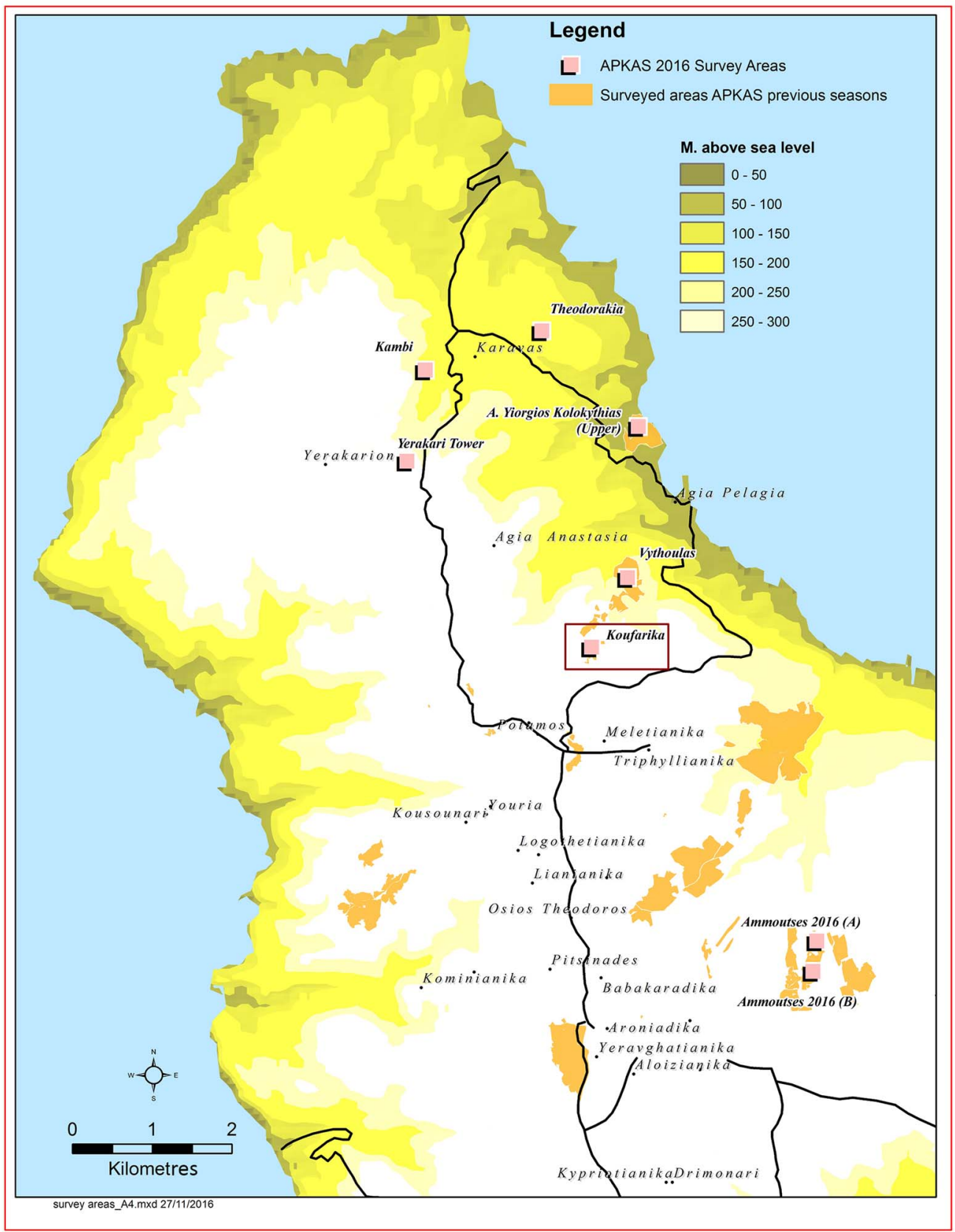

Figure 2. The northern part of Kythera island where the areas surveyed by the APKAS project are indicated with orange shading. The site of Koupharika-Krotiria is indicated in the red box (map courtesy of Richard McNeil). 


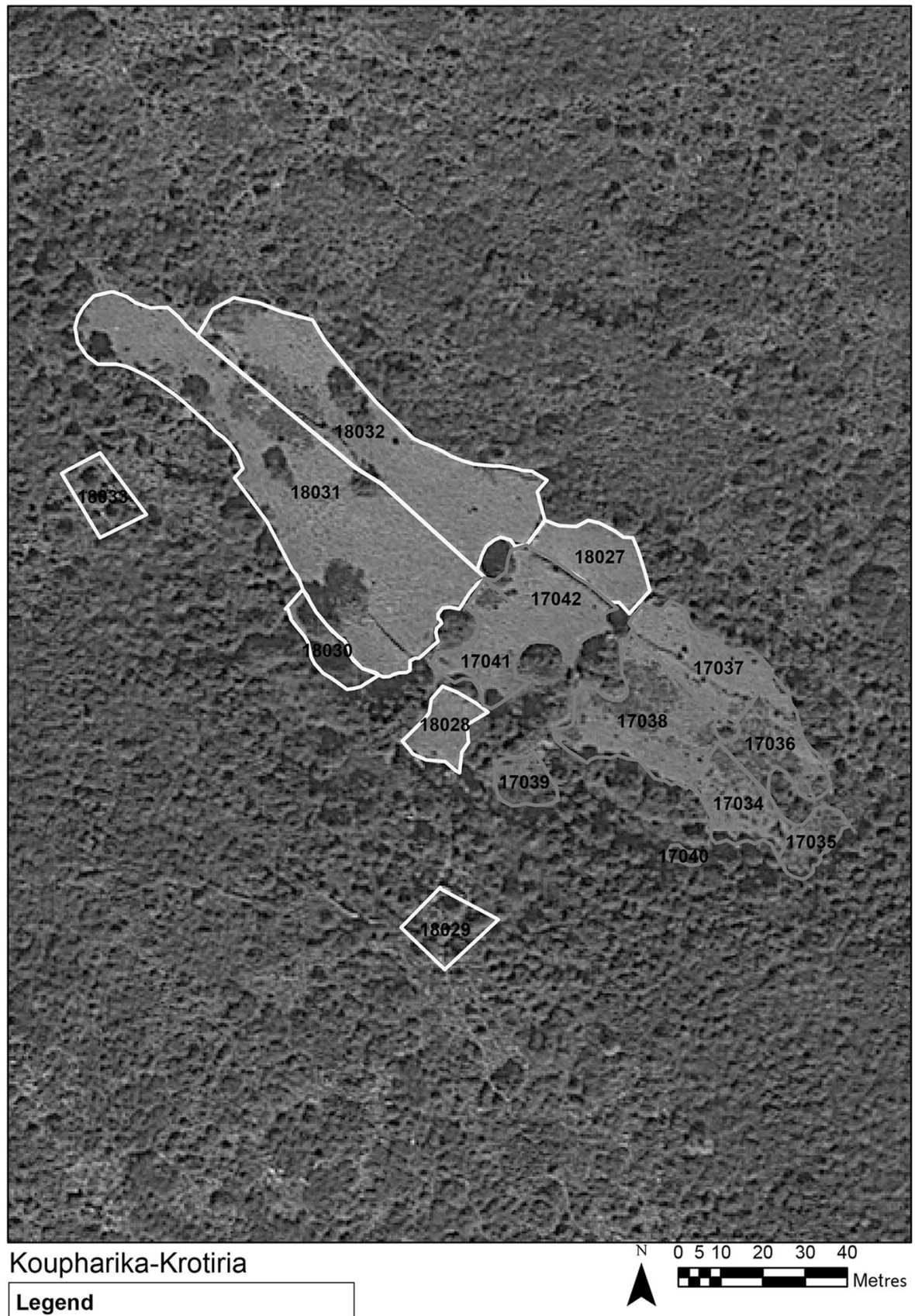

Legend

2017 Koupharika-Krotiria Survey Units

2018 Koupharika-Krotiria Survey Units

Figure 3. Koupharika-Krotiria discovery units (DUs)

(C) Antiquity Publications Ltd, 2019 

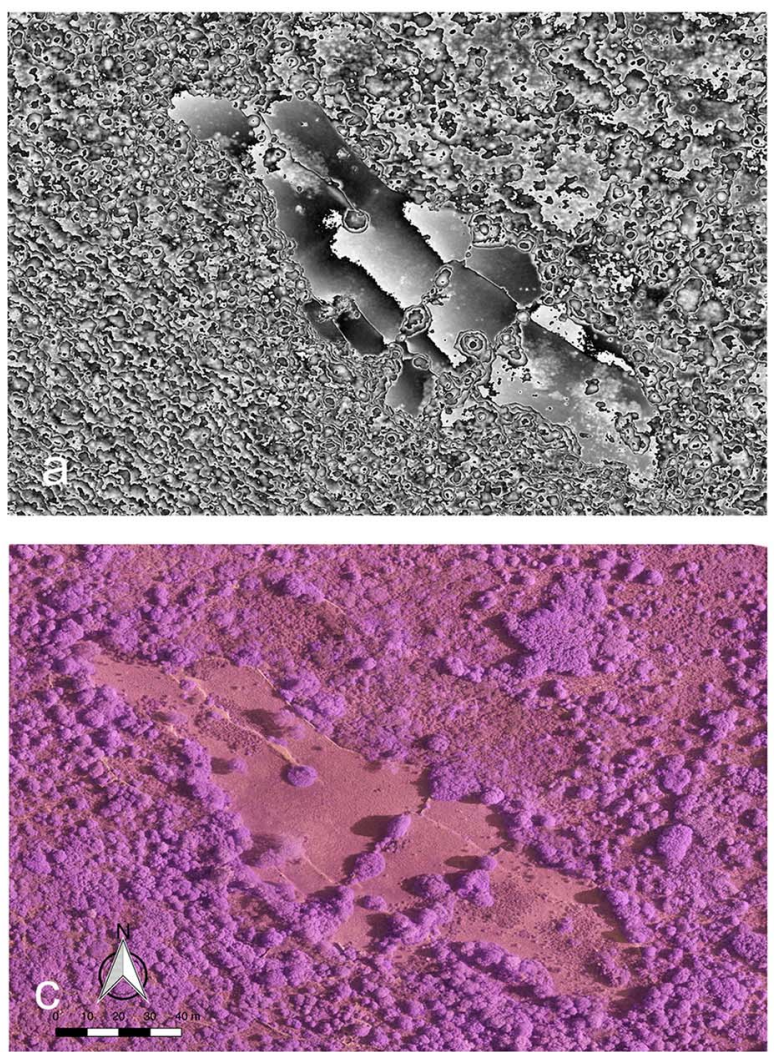
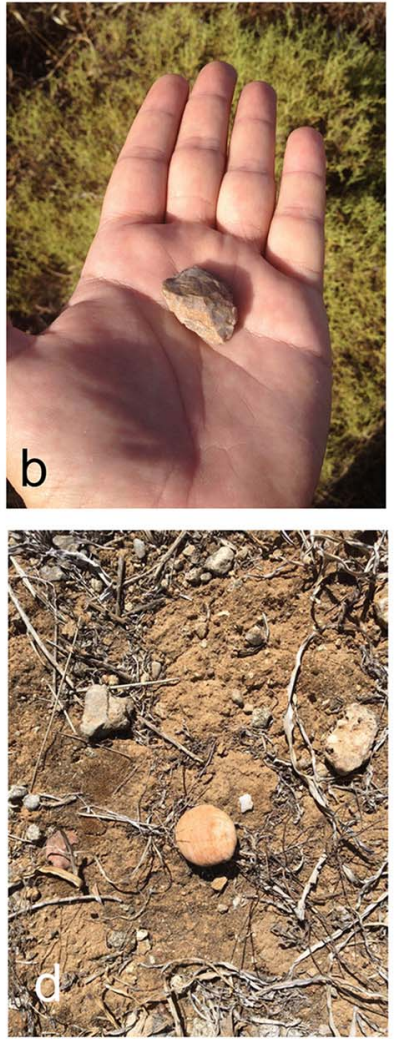

Figure 4. a) Digital surface model of the Koupharika-Krotiria site. Lithics were only recorded in the lighter areas of the model where the ground visibility was high (courtesy of John Fardoulis); b) a small quartz flake; c) orthophotograph of Koupharika-Krotiria site. Photographs were taken with the use of a modified camera with the removal of the IR filter, so that vegetation thus appears in magenta (courtesy of John Fardoulis); d) the hammerstone with traces of quartz debitage (photograph by L. Tzortzopoulou).

began a three-year campaign aiming to contextualise more broadly the data from the project's earlier seasons, and to undertake detailed work at new sites with strong archaeological potential.

\section{Field methodology}

The APKAS's methods are based on non-invasive intensive survey conducted in context units (discovery units-DU; Figure 3). The APKAS's DUs do not have predetermined dimensions, nor do they follow a pre-established grid. Their defining borders usually follow landscape features and modern field boundaries. DUs in APKAS's methodological framework are a flexible tool that can be adapted to the varying needs of different localities. As with excavation units, DUs are interpretational and are designed to record past activities in the space analysed. Field walkers move in the same direction in parallel trajectories and at pre-arranged

(C) Antiquity Publications Ltd, 2019 

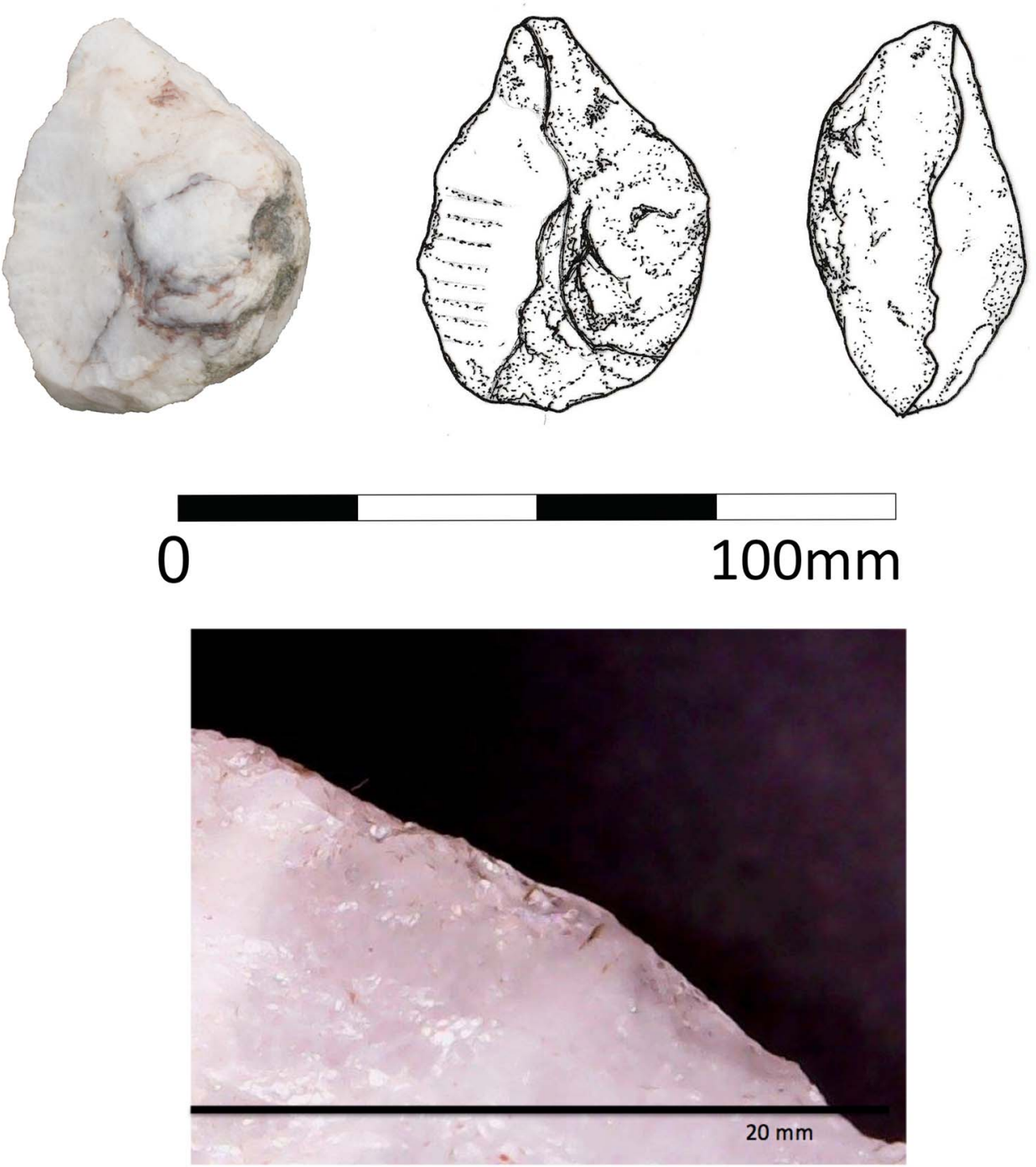

Figure 5. Top) the quartz cleaver (photograph and drawing by K.P. Trimmis \& V. Alexander); bottom) microphotography of the cleaver's cutting edge.

spacing within the DUs, noting human-made features and artefacts. Each DU's location is premarked with a GPS unit. In the more recent campaigns (2016-2017), the mapping was also based on 3D models developed using photogrammetry and images captured using an unmanned aerial vehicle (UAV).

\section{The Koupharika-Krotiria site and the quartz concentrations}

Among the areas in which the APKAS resumed its survey campaigns, the KoupharikaKrotiria site is possibly the only one that can offer potential evidence for early human activity. (c) Antiquity Publications Ltd, 2019 

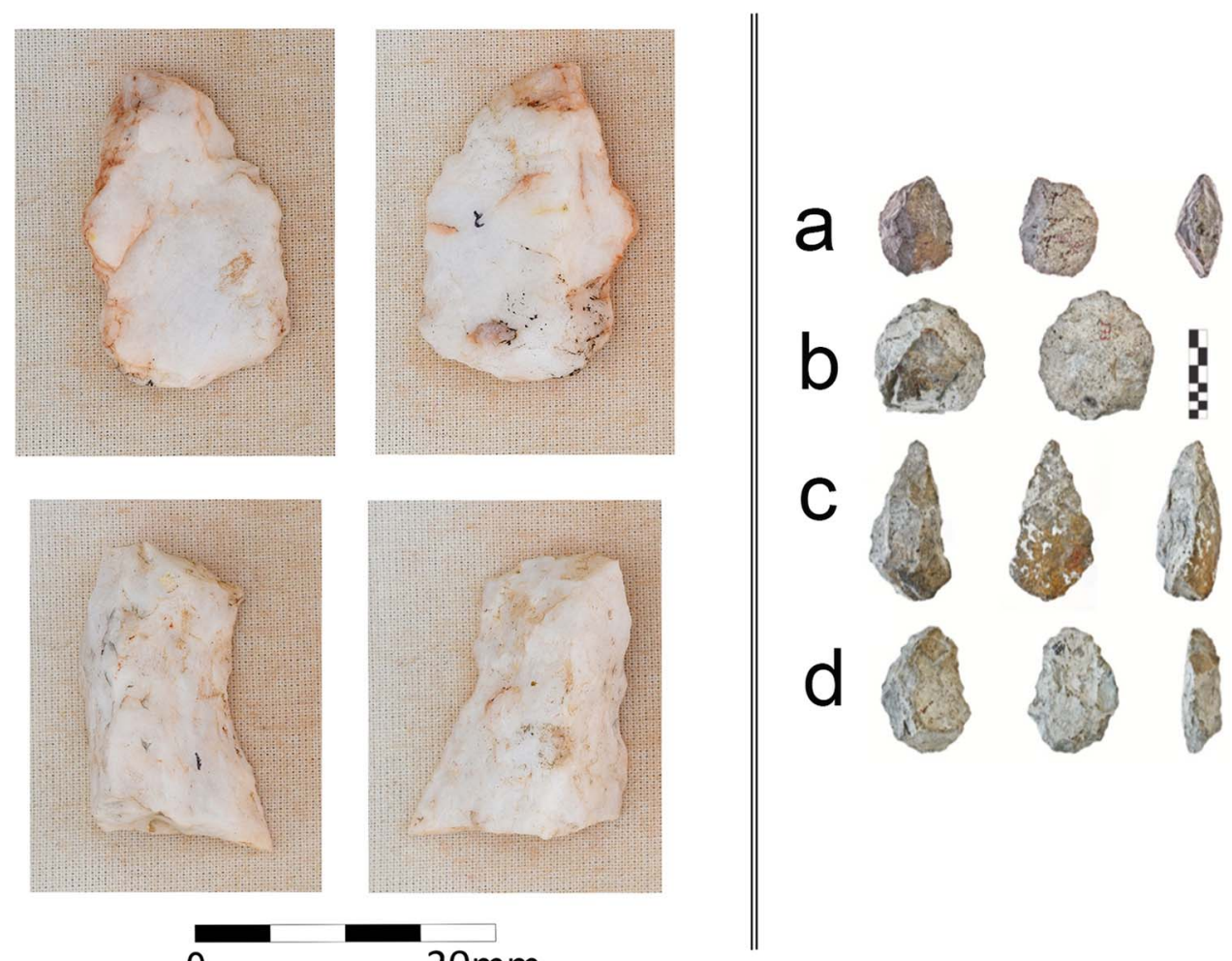

Figure 6. Left) the Koupharika-Krotiria scraper (top) and a possible scraper (bottom); right) tools from Rodaphnidia-Lisvori Lesvos (image reproduced with permission from Galanidou et al. 2016).

The site is located on an almost inaccessible wild plain, close to the Koupharika hamlet east of Potamos (Figure 1). To the west of this open plain are steep cliffs, the area beyond which is heavily wooded.

On the open plain of Koupharika-Krotiria, the APKAS team members walked nine DUs (Figure 2). At the south-eastern end of the plain, two quartz stone artefacts, a U-shaped tool (possibly a cleaver) and a scraper were found, along with a hammer-stone and a significant quantity of quartz debitage (67 quartz flakes) (Figure 4). As the methodology employed by the APKAS in its second series of campaigns does not involve any removal of artefacts, only the cleaver was drawn on site and Dino LiteX microphotographs were taken of it. Once a special permit was issued in 2018, the find was collected and deposited with the Piraeus Archaeological Museum. No polish was observed, but several striations can be seen in two separate sections of the specimen's working edge. The orientation of the striations perpendicular to the working edge suggests a striking or hacking motion rather than a reciprocal cutting one (Mansur-Franchomme 1986) (Figure 5). Macroscopically, the Koupharika-Krotiria cleaver and scraper look very similar to the Lower Palaeolithic quartz tools from Plakias in south-western Crete (see Runnels et al. 2015) and to the tools from Rodaphnidia-Lisvori in Lesvos (Figure 6). The Acheulean tools at Plakias were also initially noted during a similar

(C) Antiquity Publications Ltd, 2019 
surface reconnaissance expedition. As quartz stone tools are very difficult to date on their morphological characteristics alone, however, we cannot yet argue that the KoupharikaKrotiria lithics definitely date to the Lower Palaeolithic, and it is possible that they could date to a later prehistoric period.

\section{A spotlight on Aegean prehistory?}

It is still premature to state that the material noted at Koupharika-Krotiria provides evidence that Kythera may have served as a link in a chain that connected the Greek mainland to Crete in deep antiquity. Nor can this material provide answers to the questions posed by Runnels et al. (2015: 152) concerning what part was played by the coastal shelf of the Mediterranean, or-more specifically — of the Aegean, as a corridor for hominid dispersals. KoupharikaKrotiria, however, places the island of Kythera on the growing list of locations that may offer added information on early occupation of Aegean islands. Further work will contribute to the clarification of questions and interpretations concerning movement and connectivity in the early prehistory of the Eastern Mediterranean.

\section{Acknowledgements}

The APKAS thanks the Australian Archaeological Institute at Athens, the University of Sydney, The Ohio State University, The College of Wooster, the Nicholas Anthony Aroney Trust and Cardiff University for their support. The APKAS is also thankful to the Director of the Ephoreia of Antiquities of Western Attica, the Piraeus and Islands, Stella Chrysoulaki and the Ephoreia's staff for all their help.

\section{References}

Coroneos, C., L. Diacopoulos, T.E. Gregory, I. Johnson, J. Noller, A.S. Paspalas \& A. Wilson. 2002. The Australian Paliochora-Kythera Archaeological Survey field seasons 1999-2000. Mediterranean Archaeology 15: $126-43$.

Galanidou, N., C. Athanassas, J. Cole, G. Illiopoulos, A. Katerinopoulos, A. Magganas \& J. Mcnabb. 2016. The Acheulian site at Rodafnidia, Lisvori, on Lesvos Greece: 2010-2012, in K. Harvati \& M. Roksandic (ed.) Paleoanthropology of the Balkans and Anatolia. Human evolution and its context. 119-38 Dordrecht: Springer.

Gregory, T.E. \& L. Tzortzopoulou-Gregory. 2015. The archaeology of Kythera. Sydney: Meditarch.
Lawler, A. 2018. Neandertals, Stone Age people may have voyaged the Mediterranean. Available at http://www.sciencemag.org/news/2018/04/ neandertals-stone-age-people-may-havevoyaged-mediterranean (accessed 18 January 2019).

Mansur-Franchomme, M.E. 1986. Microscopie du matériel lithique préhistorique: traces d'utilisation, altérations naturelles, accidentelles et technologiques (Cahiers du Quaternaire 9). Bordeaux: C.N.R.S.

Runnels, C., C. DiGregorio, W.K. Wegmann, F.S. Gallen, T.F. Strasser \& E. Panagopoulou. 2015. Lower Palaeolithic artifacts from Plakias, Crete: implications for hominin dispersals. Eurasian Prehistory 11(1-2): $129-52$.

SmaIL, D.L. 2008. On deep history and the brain. Berkeley: University of California Press. 